\title{
Gimeracil Exerts Radiosensitizing Effects on Oral Squamous Cell Carcinoma Cells In Vitro and In Vivo
}

\author{
KOJI HARADA, TARANNUM FERDOUS and YOSHIYA UEYAMA
}

\author{
Department of Oral and Maxillofacial Surgery Yamaguchi University Graduate School of Medicine, Ube, Japan
}

\begin{abstract}
Background/Aim: Gimeracil or 5-chloro-2, 4dihydroxypyridine $(\mathrm{CDHP})$ has been reported to exert radiosensitization effects in cancer cells by suppressing DNA repair pathways. Here, we investigated the antitumor effect of gimeracil and radiation combination therapy against oral squamous cell carcinoma (OSCC). Material and Methods: The antitumor activity of gimeracil and/or radiation was investigated in HSC2 and/or SAS cells by growth inhibition assays and clonogenic survival assay. The expression of DNA double-strand break repair proteins were assessed by western blotting and immunohistochemistry, also fluorescent measurements of intracellular reactive oxygen/nitrogen species (ROS/RNS) were carried out in gimeracil and/or radiation-treated HSC2 cells/tumors. Results: Gimeracil and radiation combination treatment significantly inhibited OSCC cell/tumor growth and colony formation. Down-regulated expressions of DNA double-strand break repair proteins were observed in gimeracil and/or radiation treated cells/tumors. Additionally, the growth inhibitory effect of this combination treatment was associated with reactive oxygen species/reactive nitrogen species (ROS/RNS) generation. Conclusion: Gimeracil might exert radiosensitizing effects on OSCC cells.
\end{abstract}

Gimeracil is one of the component of S-1, an oral anticancer agent, which is based on the biochemical modulation of 5fluorouracil (5-FU). Briefly, S-1 consists of tegafur ((FT); prodrug of 5-FU), gimeracil (augments the activity of 5-FU by inhibiting dihydropyrimidine dehydrogenase or DPD) and potassium oxonate ((Oxo); reduces gastrointestinal toxicity by inhibiting 5-FU phosphorylation) at a molar ratio of 1:0.4:1 in order to enhance antitumor activity and to reduce gastrointestinal

Correspondence to: Dr. Koji Harada, Department of Oral and Maxillofacial Surgery, Yamaguchi University Graduate School of Medicine, 1-1-1 Minamikogushi, Ube 755-8505, Japan. Tel: +81 83622 2297, Fax: +81 836222298, e-mail: harako@yamaguchi-u.ac.jp

Key Words: Gimeracil, radiosensitization, antitumor effect, oral squamous cell carcinoma. toxicity (1). There are numerous reports of S-1 clinical trials on head and neck squamous cell carcinoma (HNSCC) patients either alone or in combination with other drugs or radiotherapy (2-5). We have also continued to treat advanced OSCC patients by radiotherapy in combination with S-1 (6). For further improvement of therapeutic effects, we have tried chemoradiotherapy with S-1 and cisplatin (CDDP). Both of these chemo-radiotherapies in combination with S-1 have shown remarkable effects on patients with advanced OSCC.

We have already reported that S-1 can sensitize human oral cancer cells to radiation and that S-1, in combination with radiation, can exert significant effects on decreasing clonogenic survival and in vivo tumor growth $(7,8)$. Briefly, S-1 must have superior radiosensitization efficacy against oral cancer (6). However, S-1 has three components as described above and it is not clear which of these components is responsible for its radiosensitization effects against OSCC. It has been well known that 5-FU has a radiosensitization effect; therefore, chemoradiotherapy with 5-FU has been clinically used for a long time (9-12). In addition, it is reported that 5-FU degradation is delayed in irradiated cells (13). As S-1 contains gimeracil that inhibits the degradation of 5-FU, irradiation might also similarly delay 5-FU degradation in S-1-treated cells. Interestingly, it was reported that gimeracil may exert radiosensitization effects in various cancer cells by suppressing homologous recombination, which is one of the repair systems of DNA double-strand break $(14,15)$. Possibly, gimeracil itself may enhance the effect of radiation in cancer cells. However, radiosensitization efficacy of gimeracil on oral squamous cell carcinoma (OSCC) has not been clarified yet.

Therefore, in this study, we investigated whether gimeracil can sensitize OSCC cells to radiation and, thus, tried to clarify the mechanisms of the antitumor effect of gimeracil and radiation combination therapy in OSCC cell lines.

\section{Materials and Methods}

Cell lines and cell cultures. OSCC cell lines (HSC2 and SAS) were obtained from Cell Bank, RIKEN BioResource Center (Ibaraki, Japan). Cells were cultured in Dulbecco's modified Eagle's medium (DMEM) (Sigma-Aldrich, St. Louis, MO, USA) supplemented with 
$10 \%$ fetal bovine serum (FBS) (Thermo Fisher scientific Inc., Waltham, MA, USA), $100 \mu \mathrm{g} / \mathrm{ml}$ streptomycin, 100 units $/ \mathrm{ml}$ penicillin (Thermo Fisher scientific) at $37^{\circ} \mathrm{C}$ in a humidified atmosphere containing $5 \% \mathrm{CO}_{2}$.

Drug and radiation treatments. Gimeracil was obtained from Taiho Pharmaceutical Co., Ltd., (Tokyo, Japan). The drug was easily dissolved in the culture medium described above. Cells were irradiated using an X-ray irradiator (MBR-1505R2, $150 \mathrm{kV}, 5 \mathrm{~mA}$ filter: $1.0 \mathrm{~mm}$ aluminum; Hitachi Medico, Tokyo, Japan).

In vitro cell growth assay. Cells $\left(5 \times 10^{3}\right.$ cells per well) were seeded on 96-well plates (Becton Dickinson Labware, Franklin lakes, NJ USA) in DMEM supplemented with $10 \%$ FBS and antibiotics. Twenty-four hours later, the cells were either treated with gimeracil $(0.1,1.0$ and $10 \mu \mathrm{g} / \mathrm{ml})$, exposed to radiation (RT) in X-ray irradiator $(0,2,5$ and $10 \mathrm{~Gy})$ or both. After $24 \mathrm{~h}, 48 \mathrm{~h}, 72 \mathrm{~h}$ or $96 \mathrm{~h}, 3-(4,5-$ dimethylthiazol- 2-yl)-2, 5-diphenyltetrazolium bromide (MTT) was added to each well $(25 \mu \mathrm{l} /$ well $)$ and incubated for $4 \mathrm{~h}$. Then, MTT solution was removed and dimethyl sulfoxide (100 $\mu \mathrm{l} /$ well $)$ was added to the plate and, finally, the absorbance was measured with a spectrophotometer (BioRad Laboratories, Hercules, CA, USA) at optical density $490 \mathrm{~nm}$ (OD 490). All assays were run in triplicate.

Clonogenic survival assay. Log-phase cells were trypsinised, counted and plated in triplicate per data point into 6 -well plates $\left(2 \times 10^{4}\right.$ cells per well). Twenty-four hours later, cells were treated with gimeracil $(10$ $\mu \mathrm{g} / \mathrm{ml})$, incubated at $37^{\circ} \mathrm{C}$ for $1 \mathrm{~h}$ before irradiation with X-rays $(0 \sim 15$ Gy). Then, the culture medium was replaced with fresh DMEM with $10 \% \mathrm{FBS}$ and returned to the $37^{\circ} \mathrm{C}$ incubator for nine days. Colonies were fixed with $3: 1$ methanol/acetic acid and stained with hematoxyline (Mutou chemicals, Tokyo, Japan). Colonies were counted by eye, with a cut-off of $50 \%$ viable cells. The surviving fraction (SF) was calculated as mean colonies/(cells inoculated $\times$ plating efficiency). Experiments were repeated at least 3 times. Then, clonogenic survival curves were plotted.

Western blotting. Cells were treated with gimeracil $(0,5$ and $10 \mu \mathrm{g} / \mathrm{ml})$ after radiation ( $5 \mathrm{~Gy}$ ). After $24 \mathrm{~h}, 48 \mathrm{~h}$ or $72 \mathrm{~h}$ treatment, cells were lysed with RIPA Buffer (Thermo scientific, Rockford, IL, USA). Whole cell lysates were subjected to electrophoresis on $10 \%$ sodium dodecyl sulfate (SDS)-polyacrylamide gels and, then, transferred to a polyvinylidene difluoride (PVDF) membrane. The membranes were incubated with the anti-Rad 51 rabbit polyclonal antibody (Santa Cruz Biotechnology, Inc., Santa Cruz, CA, USA), anti-Rad 50 mouse monoclonal antibody (Santa Cruz), anti-Ku80 rabbit polyclonal antibody (Santa Cruz), anti-Ku70 mouse monoclonal antibody (Santa Cruz), anti-DNA-PKcs mouse monoclonal antibody (Santa Cruz), antiXRCC4 rabbit polyclonal antibody (Santa Cruz), anti-p-Akt mouse monoclonal antibody (Santa Cruz) or anti-Akt mouse monoclonal antibody (Santa Cruz). The antibody was detected using a chromogenic immunodetection system, WesternBreeze (Thermo Fisher scientific), according to the manufacturer's instructions. Also, anti- $\alpha$ tubulin monoclonal antibody (Santa Cruz) was used for normalization of Western blot analysis.

Fluorescent measurement of intracellular reactive oxygen/nitrogen species $(R O S / R N S)$. Cells were cultured in DMEM medium with $10 \%$ FBS on a non-coat $35-\mathrm{mm}$ dish containing $14 \mathrm{~mm}$ round glass coverslips (D110300, Matsunami Glass bottom dish; Matsunami glass ind., Ltd., Tokyo, Japan). Cells were equilibrated with acetooxymethyl esters of dihydro-2', 7'-dichlorofluorescein (DCF) (5 mM) and fura-2 $(2 \mathrm{mM})$ in phenol red-free RPMI 1640 supplemented with $10 \mathrm{mM}$ HEPES ( $\mathrm{pH}$ 7.4) for $30 \mathrm{~min}$ at room temperature. Cells were rinsed with the same buffer without dye and incubated for an additional 30-min period before mounting in a perfusion chamber for microscopic analysis. Then, cells were treated with gimeracil alone $(10 \mu \mathrm{g} / \mathrm{ml})$, radiation alone (5 Gy) or combination of both gimeracil and radiation $(10 \mu \mathrm{g} / \mathrm{ml}$ of gimeracil plus $5 \mathrm{~Gy}$ of radiation). DCF fluorescence was monitored with excitation at $490 \mathrm{~nm}$ and emission at $530 \mathrm{~nm}$. Fura-2 fluorescence was simultaneously monitored at an excitation wavelength of $360 \mathrm{~nm}$ with emission at $530 \mathrm{~nm}$. Imaging system with a cooled CCD camera CoolSNAP FX (Roper Scientific, Tucson, AZ, USA), imaging software MetaFluor (Universal Imaging Corporation, Downingtown, PA, USA) and an inverted microscope IX71 (Olympus, Tokyo, Japan) were used for analysis. The computer coordinates excitation filter movement with image-capture and calculates intensity ratios of the DCF/fura- 2 in the time course. Individual cells and a background area were delimited using the fura2 or brightfield images. The measured fluorescence signal was the average pixel value for the entire cell minus the average background pixel value. Because dihydro-DCF is readily photooxidized, a $0.1 \mathrm{~nm}$ neutral density filter was used with the $490-\mathrm{nm}$ excitation filter to minimize photooxidation. Measurements were made every 30 second with a 0.5 -second acquisition time (16).

Nude mice and breeding. Female athymic nude mice with CAnN.Cg-Foxnlnu/CrlCrlj genetic background (CLEA Japan, Inc., Tokyo, Japan) were purchased at 4 weeks of age and kept under sterile conditions in a pathogen-free environment. The mice were kept in temperature-controlled rooms and provided with sterile water and food ad libitum. All manipulations were carried out aseptically inside a laminar flow hood. The mice were maintained and handled in accordance with the Guidelines for Animal Experimentation of Yamaguchi University.

In vivo tumor growth assay. The effect of combined gimeracil treatment and radiation exposure was assessed by inoculation of cells into 5-week-old female athymic nude mice. Cells $\left(1 \times 10^{6}\right)$ were suspended in $0.1 \mathrm{ml}$ of serum-free medium and injected into the subcutaneous tissue of mice (average weight of $15.0 \mathrm{~g}$ ) using a 27gauge needle. Tumors at the inoculation site were monitored and measured. When the tumors reached about $100 \mathrm{~mm} 3$ in volume, they were divided into 4 groups, i.e. control group, gimeracil group, radiation (RT) group and gimeracil plus radiation combination (gimeracil + RT) group. Briefly, mice in control group were administered orally via a gastric tube with $0.5 \%$ hydroxypropylmethylcellulose ((HPMC); Daiichi seiyakukogyo, Kyoto, Japan) in a volume of $0.1 \mathrm{ml} / 10 \mathrm{~g}$ body weight for 3 weeks (5 times/week). Gimeracil was suspended in autoclaved $0.5 \%$ sodium HPMC in sterile conditions and, subsequently, homogenized by stirring. Mice in gimeracil group were administered orally with gimeracil (2.91 $\mathrm{mg} / \mathrm{kg} /$ day) for 3 weeks ( 5 times/week). Mice in the RT group were irradiated (1.5 Gy/day) for 3 weeks ( 5 times/week). Mice in gimeracil + RT group were administered orally with gimeracil $(2.91 \mathrm{mg} / \mathrm{kg} /$ day $)$ for 3 weeks ( 5 times/week) and also irradiated (1.5 Gy/day) for 3 weeks ( 5 times/week). The size of these tumors was measured every two days and the relative tumor volumes were calculated. At the end of the 3 weeks of treatment, mice were sacrificed and the tumors were dissected out, fixed in neutral-buffered formalin and embedded in paraffin for further study. 

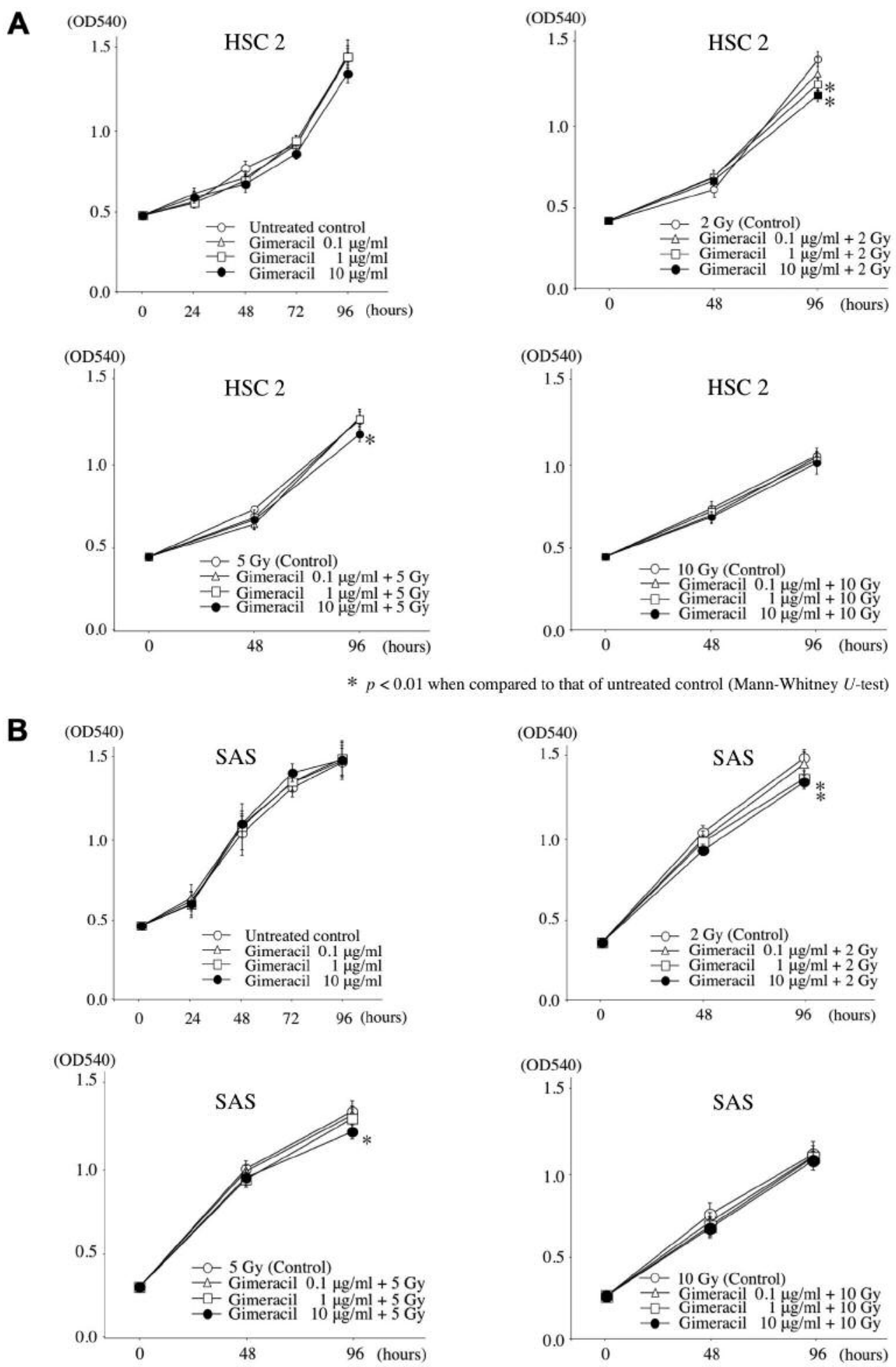

$* p<0.01$ when compared to that of untreated control (Mann-Whitney $U$-test)

Figure 1. Effect of gimeracil and radiation on cell growth inhibition in vitro. Inhibition of cell growth was evaluated by the MTT assay. (A) Gimeracil alone did not inhibit the growth of HSC2 cells. However, combined treatment of gimeracil and radiation (2 Gy or 5 Gy) significantly inhibited the growth of HSC2 cells compared to either agent alone or the untreated control.(B) Gimeracil itself did not inhibit the growth of SAS cells, whereas combined treatment of gimeracil and radiation (2 Gy or 5 Gy) inhibited the growth of SAS cells significantly compared to other treatments. Error bars represent the standard deviation of the mean of three independent experiments. OD, optical density. * $p<0.01$ when compared to that of control (Mann-Whitney's U-test). 


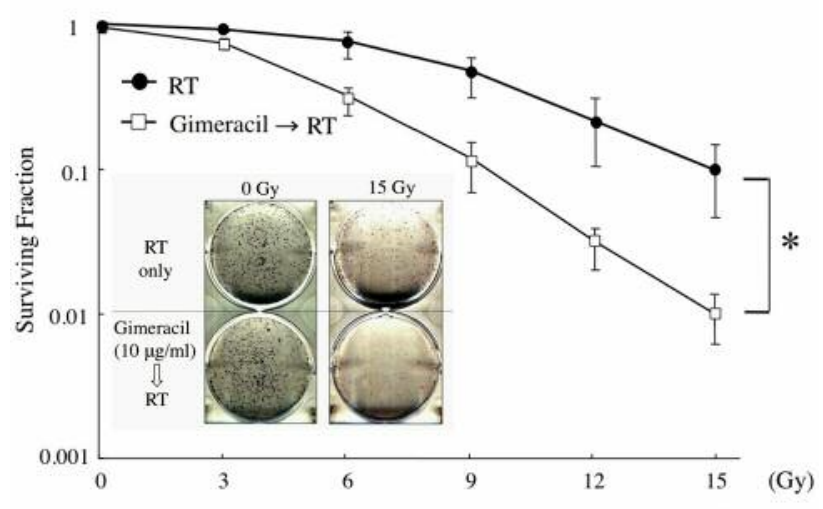

Surviving Fraction $=$ mean colonies $/$ cells inoculated $\times$ plating efficiency

$$
* p<0.01 \text { one way ANOVA }
$$

Figure 2. Effect of gimeracil and radiation on colony formation. Clonogenic survival curves for HSC2 cells treated with gimeracil $(10 \mu \mathrm{g} / \mathrm{ml})$ and radiation $(R T, 0 \sim 15 \mathrm{~Gy})$. Gimeracil and RT combination treatment was more effective in decreasing colony formation than radiation alone. Error bars represent the standard deviation of the mean of three independent experiments (radiation only $\bullet$, gimeracil before radiation $\square$ ). OD, optical density. ${ }^{*} p<0.01$ by one-way ANOVA.

Immunohistochemistry. The avidin-biotin complex immunohistochemical technique was used to detect DNA double strand break repair proteins, apoptosis and survival signal in tissue specimens, using the EnVision ${ }^{\circledR}$ System-HRP kit (Dako, Glostrup, Denmark). Four- $\mu$ m-thick paraffin-embedded tissue sections were deparaffinized in xylene and rehydrated through graded alcohols. Endogenous peroxidase was quenched with a $0.3 \%$ hydrogen peroxide/methanol mixture for $30 \mathrm{~min}$. Sections were rinsed and pre-incubated with $2 \%$ blocking serum for $30 \mathrm{~min}$, followed by incubation with the anti-Rad 50 mouse monoclonal antibody (Santa Cruz), anti-Ku 70 mouse monoclonal antibody (Santa Cruz), antiKu80 rabbit polyclonal antibody (Santa Cruz), anti-DNA-PKcs mouse monoclonal antibody (Santa Cruz) and anti-p-Akt mouse monoclonal antibody (Santa Cruz) for $8 \mathrm{~h}$ at $4{ }^{\circ} \mathrm{C}$. After rinsing the tissue sections in phosphate buffered saline (PBS) for $10 \mathrm{~min}$, the antibody was detected using the EnVision ${ }^{\circledR}$ System-HRP kit according to the manufacturer's instructions. Tissues were, finally, rinsed in PBS for $5 \mathrm{~min}$ and tap water for $5 \mathrm{~min}$ and, then, counterstained with hematoxylin (Mutou chemicals) for $1 \mathrm{~min}$. The tissue sections were subsequently dehydrated in graded ethanol, cleared in Histoclear and mounted with glass coverslips using a mixture of distyrene (a polystyrene), a plasticiser (tricresyl phosphate) and xylene (DPX). Each run included positive and negative controls.

TUNEL (terminal deoxynucleotidyl transferase (Tdt)-mediated nickend labeling) assay. To detect apoptotic cells in mice tumor tissues, TUNEL assay was performed in 4 - $\mu$ m-thick paraffin sections of tumor tissues using a DeadEnd ${ }^{\mathrm{TM}}$ Colorimetric TUNEL System according to the manufacturer's instructions (Promega Corporation, Madison, WI, USA). Briefly, the sections were incubated in $20 \mu \mathrm{g} / \mathrm{ml}$ proteinase $\mathrm{K}$ for $15 \mathrm{~min}$. Endogenous peroxidase of cells was blocked by incubating in a $3 \%$ hydrogen peroxide solution for $5 \mathrm{~min}$

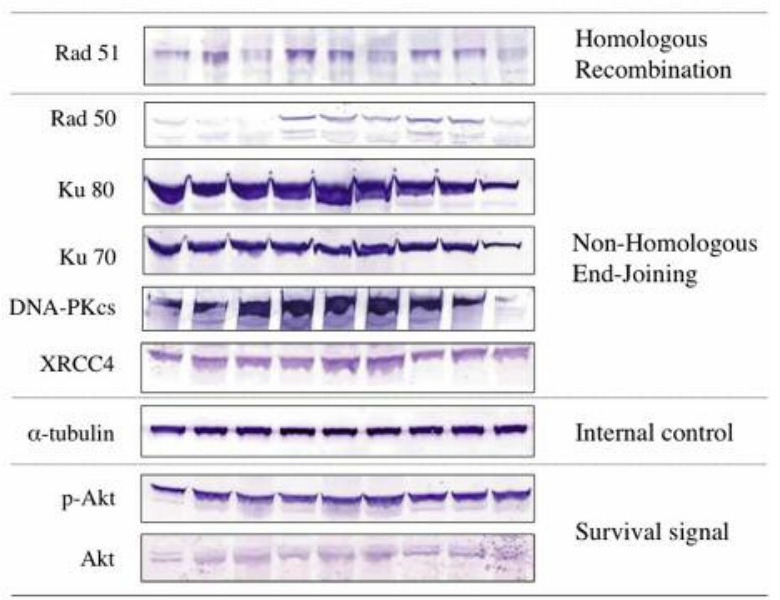

Gimeracil $\quad \begin{array}{llllllllll}0 & 5 & 10 & 0 & 5 & 10 & & 0 & 5 & 10\end{array}(\mu \mathrm{g} / \mathrm{ml})$ after RT (5Gy) $24 \mathrm{~h} \quad \frac{5 \mathrm{~h}}{72 \mathrm{~h}}$

Figure 3. Effect of gimeracil and radiation on the expression of DNA double-strand break repair and survival signal proteins in vitro. Western blotting was performed to detect the expression of DNA double strand break repair proteins in vitro. Gimeracil (5 and $10 \mu \mathrm{g} / \mathrm{ml})$ and radiation $(R T, 5 G y)$ combined treatment reduced the expression of Rad 51, Rad 50, $K u$ 80, Ku 70 and DNA-PKcs compared to radiation alone after $72 \mathrm{~h}$ of treatment. However, gimeracil and radiation combination treatment after radiation did not affect the expression of XRCC, $p$-Akt and Akt.

after rinsing in distilled water. After PBS wash, the sections were incubated with equilibration buffer $(0.05 \mathrm{M}$ phosphate buffer containing $0.145 \mathrm{M}$ sodium chloride, $\mathrm{pH} 7.4$ ) and, then, Tdt enzyme in a humidified chamber at $37^{\circ} \mathrm{C}$ for $60 \mathrm{~min}$. They were, subsequently, put into pre-warmed working strength stop wash buffer for $10 \mathrm{~min}$. After being rinsed in PBS, the sections were incubated with antidigoxigenin-peroxidase conjugate for $30 \mathrm{~min}$. Peroxidase activity, in each section, was demonstrated by the application of diaminobenzidine. Hematoxylin was used as a counterstain.

Statistical analysis. All statistical significance was set at $p<0.05$. Statistical analyses were performed using the StatView software (version 5.0J, SAS Institute Inc. Cary, NC, USA).

\section{Results}

Combined effects of gimeracil and radiation on in vitro cell growth. The growth-inhibitory effect of gimeracil and/or radiation on HSC2 or SAS cells was analyzed by MTT assay. Cells were treated with different concentrations of gimeracil $(0.1,1.0$ and $10 \mu \mathrm{g} / \mathrm{ml})$ alone for $24-96 \mathrm{~h}$. Gimeracil itself did not inhibit the growth of SAS or HSC2 cells. On the other hand, the combination treatment with gimeracil (1 and $10 \mu \mathrm{g} / \mathrm{ml}$ ) and radiation ( $2 \mathrm{~Gy}$ ) significantly inhibited the growth of SAS and HSC2 cells when compared to 2-Gy alone (control). Moreover, the combination treatment with gimeracil $(10 \mu \mathrm{g} / \mathrm{ml})$ and radiation (5 Gy) also significantly 


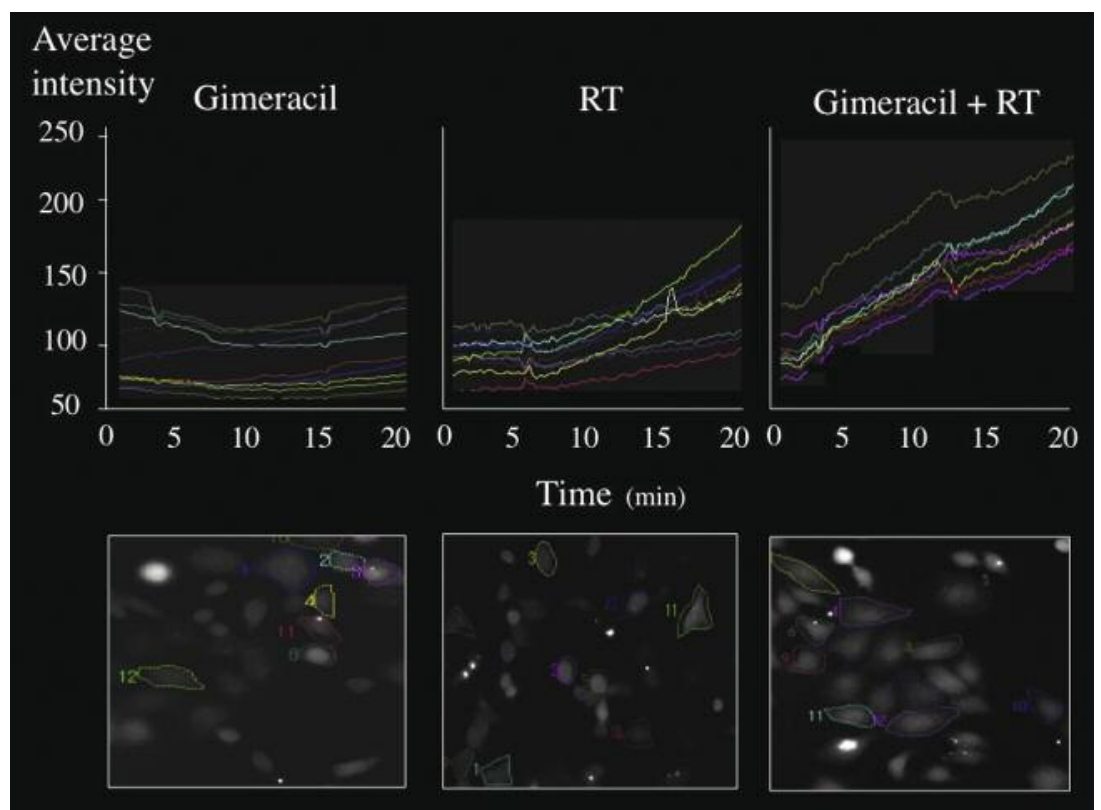

Figure 4. Combined effect of gimeracil and radiation on production of ROS/RNS. HSC2 cells were treated with gimeracil alone (10 $\mu \mathrm{g} / \mathrm{ml})$, radiation alone (RT, $5 \mathrm{~Gy})$ or combination of both gimeracil and radiation $(10 \mu \mathrm{g} / \mathrm{ml}$ of gimeracil, $5 \mathrm{~Gy}$ of radiation). The production of ROS/RNS was markedly induced by gimeracil $(10 \mu \mathrm{g} / \mathrm{ml})$ and radiation $(5 \mathrm{~Gy})$ combined treatment than either treatment alone.

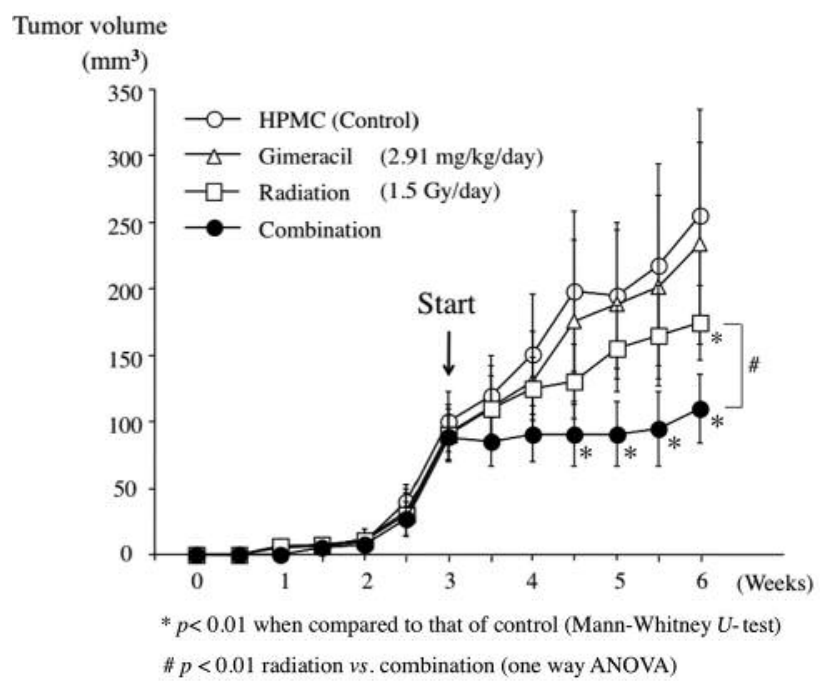

Figure 5. Effect of gimeracil and radiation on tumor growth inhibition in vivo. Nude mice with HSC2 tumor xenografts were used to examine the antitumor activity of gimeracil and/or radiation treatment. Gimeracil alone did not inhibit the growth of tumors but irradiation (RT) alone and gimeracil plus RT significantly inhibited tumor growth compared to untreated control. Moreover, combined therapy of gimeracil and radiation (gimeracil $+R T$ ) significantly inhibited tumor growth than RT or gimeracil alone. Error bars represent the standard error of the mean from five mice results $(n=5)$.

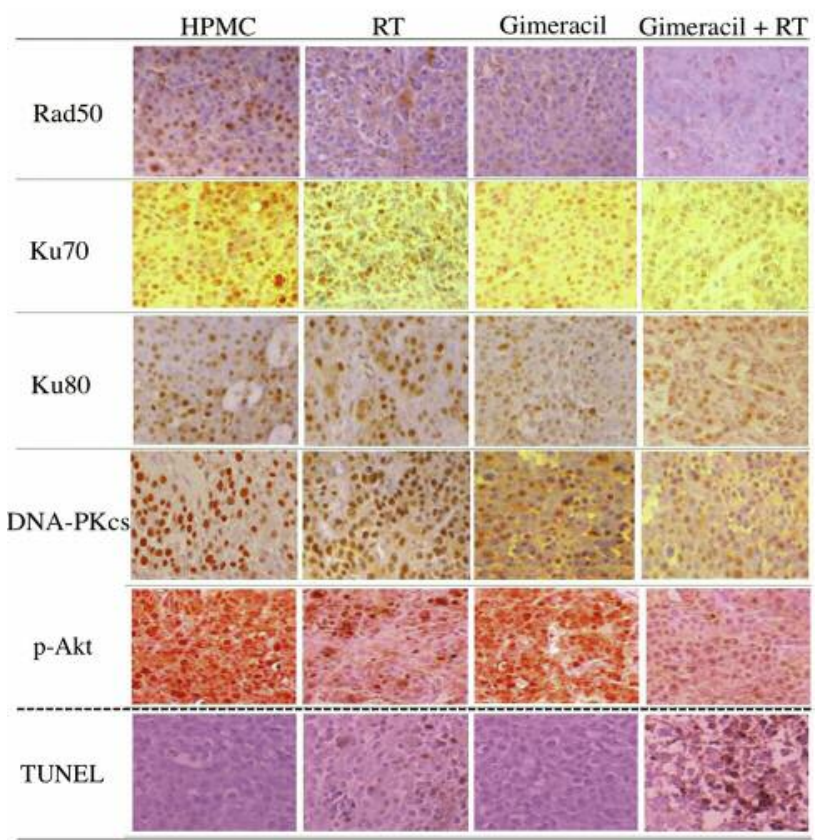

Figure 6. Effect of gimeracil and radiation on the expression of DNA double-strand break repair proteins, survival signal protein and apoptosis in vivo. Immunohistchemical staining was performed to investigate the mechanisms behind the antitumor effects of combined treatment of gimeracil and radiation. Combined treatment of gimeracil and radiation (gimeracil $+R T$ ) reduced the expression of Rad $50, K u 70$, Ku 80, DNA-PKcs and p-Akt in HSC2 tumors. On the other hand, apoptotic cells were induced by the combined treatment of gimeracil and radiation observed by TUNEL assay. 
inhibited the growth of SAS and HSC2 cells when compared to 5-Gy alone (control) (Figure 1A and 1B).

Radiosensitization effects of gimeracil in vitro. To determine whether addition of gimeracil enhances radiosensitivity (mitotic death by radiation) or not, we performed clonogenic survival assay with $\mathrm{HSC} 2$. The dose of radiation required to give an SF of $10 \%$ for HSC2 was decreased (from 14.5 to $9.4 \mathrm{~Gy}, p<0.01)$ in the presence of gimeracil $(10 \mu \mathrm{g} / \mathrm{ml})$. Thus, addition of gimeracil enhanced the radiosensitivity of HSC2 by 1.54 -fold (Figure 2).

Effect of gimeracil on the expression of DNA double strand break repair proteins and survival signal proteins in vitro. To clarify the mechanisms behind the radiosensitization efficacy of gimeracil, we examined the expression of DNA double strand break repair proteins (Rad 51, $\mathrm{Rad} 50, \mathrm{Ku} 80, \mathrm{Ku} 70$, DNA-PKcs, XRCC4) in cells by Western blotting. Gimeracil treatment ( 5 and $10 \mu \mathrm{g} / \mathrm{ml})$ and radiation $(5 \mathrm{~Gy}$ ) reduced the level of $\operatorname{Rad} 51, \operatorname{Rad} 50, \mathrm{Ku} 80$, $\mathrm{Ku} 70$ and DNA-PKcs in HSC2 after $72 \mathrm{~h}$ of treatment, but did not reduce the expression of XRCC. On the other hand, the same treatment did not affect the expression of p-Akt (survival signal protein) (Figure 3).

Combined effect of gimeracil and radiation on ROS/RNS generation. To investigate the relationship between ROS/RNS production and enhancement of radiosensitizing effects by gimeracil, the ROS/RNS-sensitive dye DCF was used in fluorescence microscopic analysis to detect ROS/RNS generation. The production of ROS/RNS was markedly induced by gimeracil $(10 \mu \mathrm{g} / \mathrm{ml})$ and radiation (5 Gy) combined treatment than either treatment alone (Figure 4).

Effect of gimeracil and radiation on tumor growth inhibition in vivo. Nude mice with HSC2 tumor xenografts were used to examine the antitumor activity of gimeracil $(2.91 \mathrm{mg} / \mathrm{kg} / \mathrm{day})$ and radiation (1.5 Gy/day) single/combination treatment. Significant growth inhibition was not observed in gimeraciltreated tumors, while radiation alone and gimeracil-radiation combination therapy significantly inhibited tumor growth compared to HPMC-treated tumors (untreated control). Moreover, gimeracil-radiation combination therapy showed significant growth inhibitory effect than gimeracil or radaition alone (Figure 5).

Effect of gimeracil and radiation on the expression of DNA double strand break repair proteins, survival signal and induction of apoptosis in vivo. We examined the expression of DNA double strand break repair proteins, induction of apoptosis and the expression of survival signals in the murine tumors by immunohistochemistry. The expression of DNA double strand break repair proteins $(\operatorname{Rad} 50, \mathrm{Ku} 70, \mathrm{Ku}$ 80 , DNA-PKcs) were decreased in gimeracil-treated tumors and were markedly reduced in gimeracil-treated and irradiated tumors compared to irradiated tumors or HPMCtreated tumors (untreated control). Moreover, the expression of p-Akt was markedly decreased in gimeracil-treated plus irradiated tumors, though the expression of p-Akt was not changed in gimeracil-treated tumors. Furthermore, TUNEL assay showed the induction of apoptosis in gimeracil-treated plus irradiated tumors (Figure 6).

\section{Discussion}

In the present study, we showed the radiosensitization efficacy of gimeracil on OSCC both in vitro and in vivo. Gimeracil $(0.1-10 \mu \mathrm{g} / \mathrm{ml})$ did not show cytostatic activity (Figure 1A and B) and, also, gimeracil $(2.91 \mathrm{mg} / \mathrm{kg}$ ) could not exert any antitumor activity (Figure 5). Moreover, gimeracil exerted little to almost no influence on cell survival signal (p-Akt), as well as cell proliferation (Figures 3 and 6). Furthermore, gimeracil $(2.91 \mathrm{mg} / \mathrm{kg})$ did not show remarkable weight loss in mice during in vivo experiments (data not shown). Still, gimeracil could enhance the effect of radiation in our experiments and its combination with radiation effectively suppressed OSCC cell growth in vitro and tumor growth in vivo. Therefore, gimeracil could be an attractive agent as a radiosensitizer because it may have none or few adverse effects clinically.

DNA is an important molecular target for radiationinduced damage and there are two major pathways for repairing them: homologous recombination (HR)-mediated and non-homologous end-joining (NHEJ)-mediated DNA repair pathways (17). It was reported that gimeracil enhances the radiosensitivity of OSCC through the down-regulation of DNA double-strand break repair proteins (Figures 3 and 6). Takagi et al. and Sakata et al. have reported that gimeracil may enhance the efficacy of radiotherapy through the suppression of homologous recombination (HR)-mediated DNA repair pathways $(14,15)$. Briefly, their reports support our concept of the potential of gimeracil. Our findings showed that the combination of gimeracil and radiation inhibited DNA double strand break repair system by not only suppressing HR-mediated DNA repair but also by suppressing non-homologous end-joining (NHEJ)-mediated DNA repair in the OSCC cells (Figures 3 and 6).

When DNA is damaged by irradiation and not successfully repaired, cell death may occur during its attempt to divide (mitotic death or reproductive death) or it can occur immediately before the next mitosis (interphase death) (17). It is thought that interphase death is induced by small dose of irradiation. Clonogenic survival assay is frequently used to understand a dose-effect relationship based on interphase death as a quantification method of cell radiosensitivity. Our clonogenic survival assay clearly showed the radiosensitization efficacy of gimeracil on OSCC cells (Figure 2). 
Radiation effects in cells may cause primary and secondary ionization events that may be initiated by reactive ROS/RNS species (17). Radiation-induced ROS/RNS might interact with signal molecules that are important for the activation of signal transduction cascades as the generation of ROS has been shown to regulate apoptosis $(17,18)$. To investigate the relationship between ROS/RNS production and enhancement of radiation-induced apoptosis by gimeracil, the ROS/RNS-sensitive dye DCF was used in fluorescence microscopy analysis to detect ROS/RNS generation (Figure 4). The production of ROS/RNS was markedly induced by the combined treatment of gimeracil and radiation than either treatment alone. ROS/RNS generated by combined treatment of gimeracil and radiation may regulate apoptotic processes of OSCC cells .

In this study, we showed that gimeracil sensitizes OSCC cells to radiation. Gimeracil can also boost the blood level of 5-FU, thereby enhancing its effect in cancer cells by inhibiting 5-FU degradation agent DPD (19). Someya et al. showed that the radiosensitizing effect of gimercail is directly connected with its DPD depletion effect in a human colorectal carcinoma cell line (20). However, we did not clarify this point in our present investigation. Interestingly, it has been reported that gimeracil could also enhance sensitivity of camptothecin and hyperthermia (21). There may still be various possible candidates for gimeracil as a combination treatment. Briefly, we may be able to apply gimeracil in clinical settings with other therapeutic agent as gimeracil may have some unknown mechanisms to increase the efficacy of other drugs, such as radiation.

\section{Acknowledgements}

This study was supported, in part, by a Grant-in-Aid for from the Japanese Ministry of Education, Science and culture.

\section{References}

1 Ooyama A, Oka T, Zhao H, Yamamoto M, Akiyama $\mathrm{S}$ and Fukushima M: Anti-angiogenic effect of 5-Fluorouracil-based drugs against human colon cancer xenografts. Cancer Letters 267: 26-36, 2008.

2 Tsukuda M, Kida A, Fujii M, Kono N, Yoshihara T, Hasegawa Y, Sugita $M$ and Chemotherapy study group of head and neck cancer: Randomized scheduling feasibility study of S-1 for adjuvant chemotherapy in advanced head and neck cancer. Br J Cancer 93: 884-889, 2005.

3 Tsukuda M, Ishitoya J, Mikami Y, Matsuda H, Horiuchi C, Taguchi T, Satake K, Kawano T, Takahashi M, Nishimura G, Kawakami M, Sakuma Y, Watanabe M, Shiono O, Komatsu M and Yamashita Y: Analysis of feasibility and toxicity of concurrent chemoradiotherapy with S-1 for locally advanced squamous cell carcinoma of the head and neck in elderly cases and/or cases with comorbidity. Cancer Chemother Pharmacol 64: 945-952, 2009.
4 Kuratomi Y, Satoh S, Monji M, Yokogawa K, Suzuki K, Shimazu R, Tokumaru S and Inokuchi A: A comparative study of concurrent chemoradiotherapy with S-1 or CDDP for pharyngeal or laryngeal cancer. Gan To Kagaku Ryoho 37: 1471$1476,2010$.

5 Kubota K, Sato H, Sakaki H, Nakagawa H, Kon T, Narita N, Kobayashi W and Kimura $\mathrm{H}$ : A case of submandibular gland cancer in elderly patients showed significant effect by S-1 and intravenous docetaxel chemotherapy concurrent with radiotherapy. Gan To Kagaku Ryoho 37: 1937-1940, 2010.

6 Sato $M$ and Harada K: Phase I study of concurrent radiotherapy with S-1 for oral squamous cell carcinoma. Gan To Kagaku Ryoho 33: 179-183, 2006 (in Japanese with English abstract).

7 Harada K, Kawaguchi S, Supriatno, Onoue T, Yoshida H and Sato M: Enhancement of apoptosis in salivary gland cancer cells by the combination of oral fluoropyrimidine anticancer agent (S1) and radiation. Int J Oncol 25: 905-911, 2004.

8 Harada K, Kawaguchi S, Supriatno, Onoue T, Yoshida H and Sato M: Combined effects of the oral fluoropyrimidine anticancer agent, S-1 and radiation on human oral cancer cells. Oral Oncol 40: 713-719, 2004.

9 Smalley SR, Kimler BF and Evans RG: 5-Fluorouracil modulation of radiosensitivity in cultured human carcinoma cells. Int J Radiat Oncol Biol Phys 20: 207-211, 1991.

10 Nakajima Y, Miyamoto $T$, Tanabe M, Watanabe I and Terasima T: Enhancemet of mammalian cell killing by 5fluorouracil in combination with X-rays. Cancer Res 39: 3763-3767, 1979.

11 Berry RJ: Effects of some metabolic inhibitors on x-ray doseresponse curves for the survival of mammalian cells in vitro, and on early recovery between fractionated $\mathrm{x}$-ray doses. Br J Radiol 39: 458-463, 1966.

12 Lo TC, Wiley AL Jr, Ansfield FJ, Brandenburg JH, Davis HL Jr, Gollin FF, Johnson RO, Ramirez G and Vermund H: Combined radiation therapy and 5-fluorouracil for advanced squamous cell carcinoma of the oral cavity and oropharynx: a randomized study. AJR Am J Roentgenol 126: 229-235, 1976.

13 Matsubara S: Fundamental remarks on combination radiotherapy with anti-neoplastic agents. Jpn J Cancer Clin 45: 271-273, 1999.

14 Takagi M, Sakata K, Someya M, Tauchi H, Iijima K, Matsumoto Y, , Torigoe T, Takahashi A, Hareyama M and Fukushima M: Gimeracil sensitizes cells to radiation via inhibition of homologous recombination. Radiother Oncol 96: 259-266, 2010.

15 Sakata K, Someya M, Matsumoto Y, Tauchi H, Kai M, Toyota M, Takagi M, Hareyama M and Fukushima M: Gimeracil, an inhibitor of dihydropyrimidine dehydrogenase, inhibits the early step in homologous recombination. Cancer Sci 102: 1712-1716, 2011.

16 Leach JK, Van Tuyle G, Lin PS, Schmidt-Ullrich R and Mikkelsen RB: Ionizing radiation-induced, mitochondriadependent generation of reactive oxygen/nitrogen. Cancer Res 61: 3894-3901, 2001.

17 Schmidt-Ullrich RK: Molecular targets in radiation oncology. Oncogene 22: 5730-5733, 2003.

18 Tsang WP, Chau SP, Kong SK, Fung KP and Kwok TT: Reactive oxygen species mediate doxorubicin induced p53-independent apoptosis. Life Sci 73: 2047-2058, 2003. 
19 Shirasaka T, Shimamoto Y, Ohshimo H, Yamaguchi M, Kato T, Yonekura $\mathrm{K}$ and Fukushima M: Development of a novel form of 5 -fluorouracil derivative (S-1) directed to the potentiation of the tumor-selective cytotoxicity of 5-fluorouracil by two biochemical modulators. Anticancer Drugs 7: 548-557, 1996.

20 Someya M, Sakata K, Matsumoto Y, Tauchi H, Kai M, Hareyama $\mathbf{M}$ and Fukushima $\mathbf{M}$ : Effects of depletion of dihydropyrimidine dehydrogenase on focus formation and RPA phosphorylation. J Radiat Res 53(2): 250-256, 2012.
21 Takagi M, Sakata K, Someya M, Matsumoto Y, Tauchi H, Hareyama $M$ and Fukushima $M$ : The combination of hyperthermia or chemotherapy with gimeracil for effective radiosensitization. Strahlenther Onkol 188: 255-261, 2012.

Received June 23, 2016

Revised July 12, 2016

Accepted July 13, 2016 